\title{
Carbamoyl Functionalized Bent para-Phenylenes via an Unexpected Reaction of the Burgess Reagent with $\alpha$-Ketols
}

Sydney N. Jackson, Andrew L. Caskey, Natasha K. Narayanan, and Bradley L. Merner*

Department of Chemistry and Biochemistry, Auburn University, Auburn, AL, 36849, USA

\section{TABLE OF CONTENTS}

1. Table SI-1: Attempted dehydration and elimination reactions of $\mathbf{1 5}$

2. ${ }^{1} \mathrm{H}$ and ${ }^{13} \mathrm{C}$ NMR spectra

3. X-ray crystal structures of $\mathbf{2 3}$ and $\mathbf{2 4}$, additional data and structure refinement

1. Table SI-1: Attempted dehydration and elimination reactions of $\mathbf{1 5}$

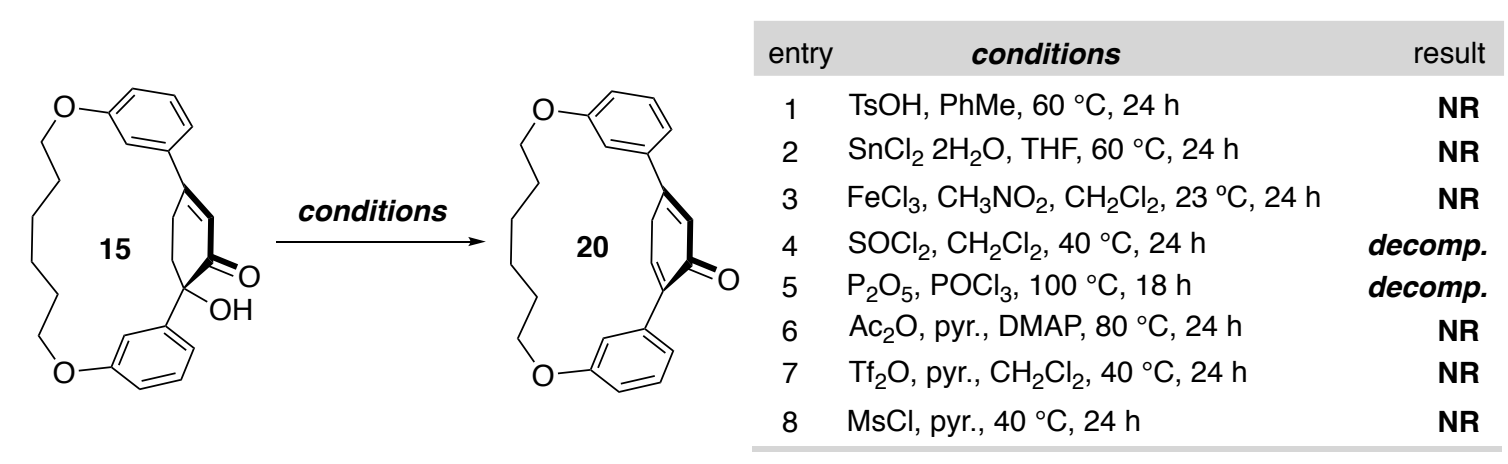

2. $\quad{ }^{1} \mathrm{H}$ and ${ }^{13} \mathrm{C}$ NMR Spectra (compounds presented in chronological order) 


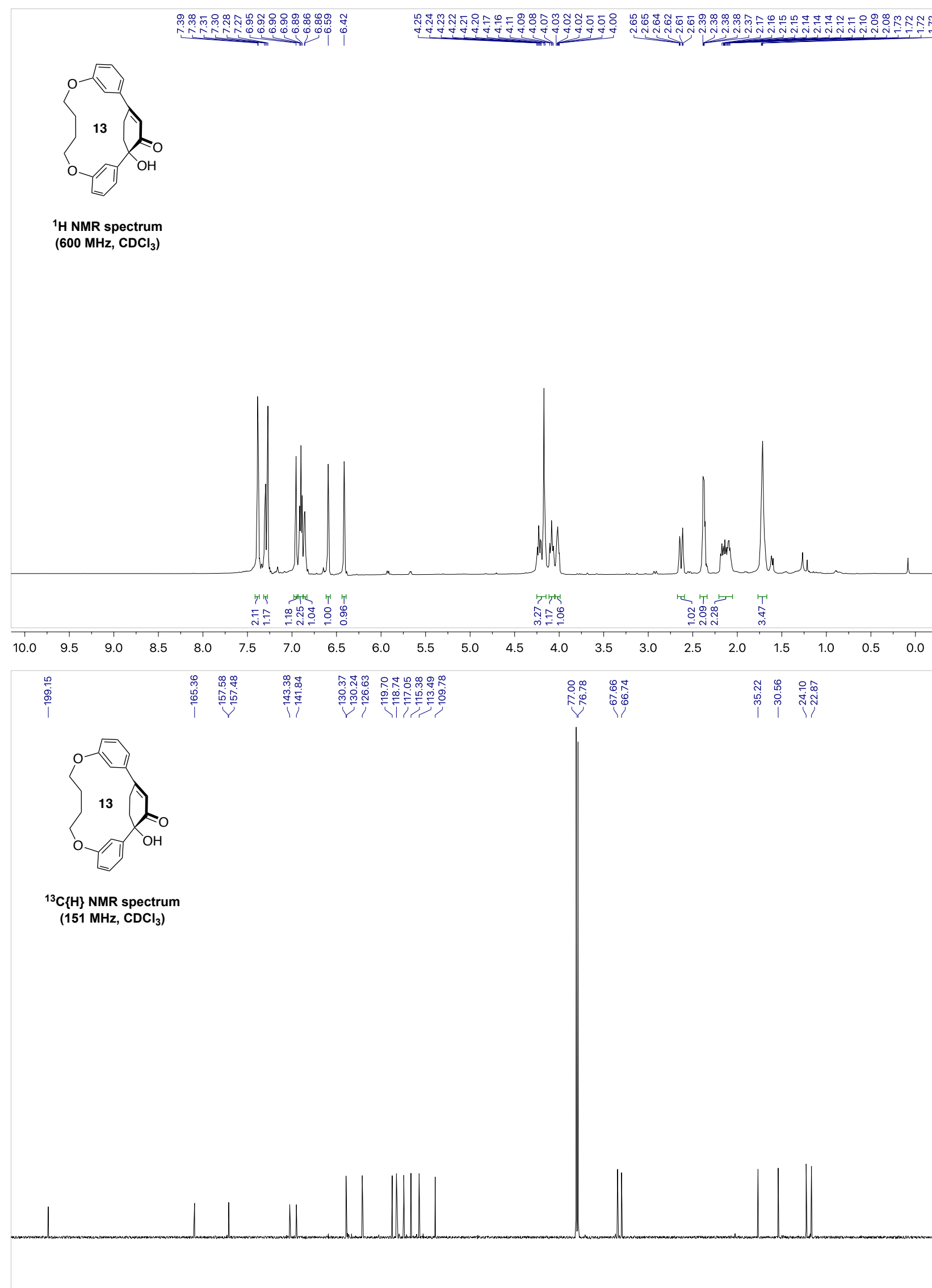

13

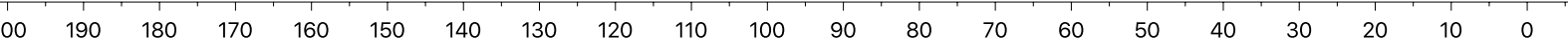

SI-2 


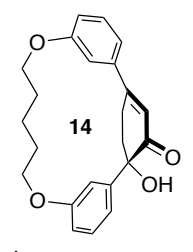

${ }^{1} \mathrm{H}$ NMR spectrum

$\left(600 \mathrm{MHz}, \mathrm{CDCl}_{3}\right)$

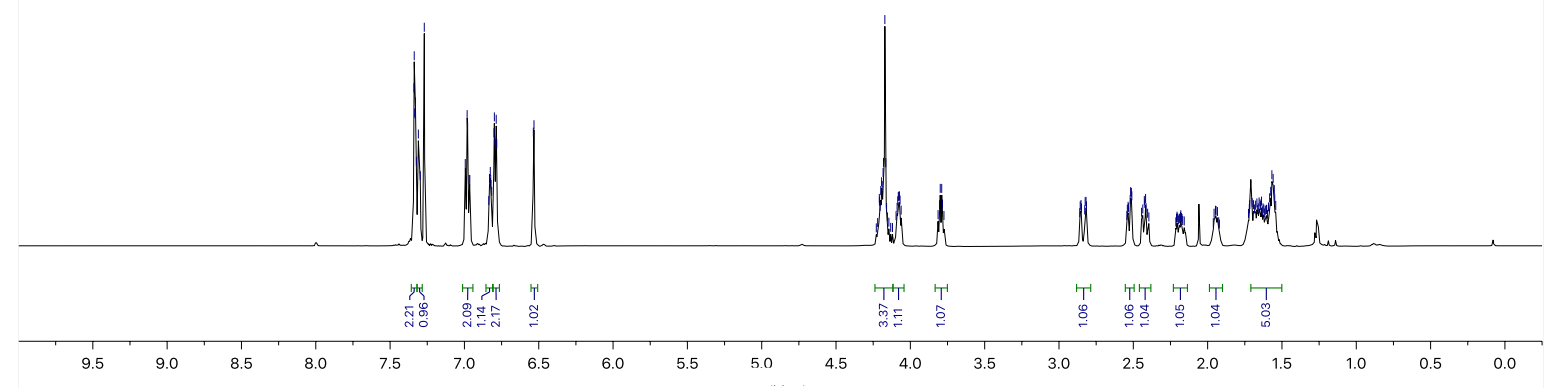

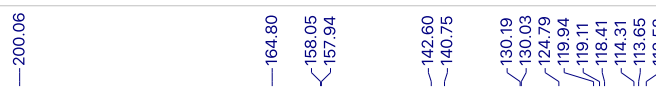

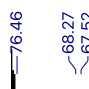

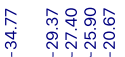

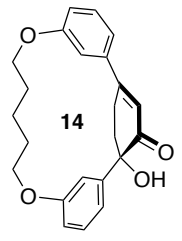

${ }^{13} \mathrm{C}\{\mathrm{H}\}$ NMR spectrum

$\left(151 \mathrm{MHz}, \mathrm{CDCl}_{3}\right)$
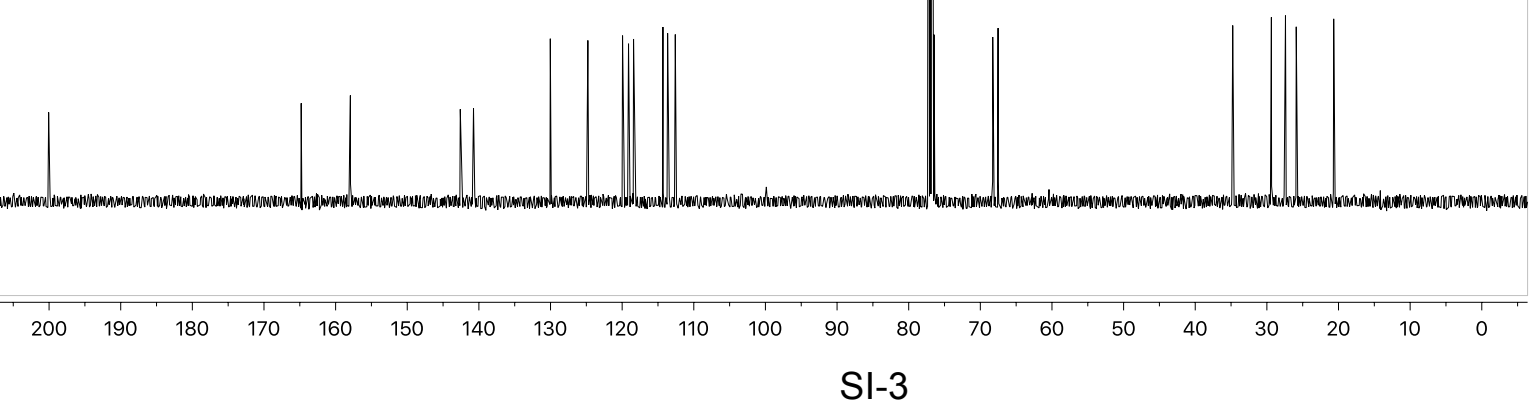


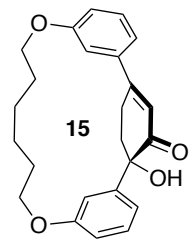

${ }^{1} \mathrm{H}$ NMR spectrum

(600 MHz, $\mathrm{CDCl}_{3}$ )
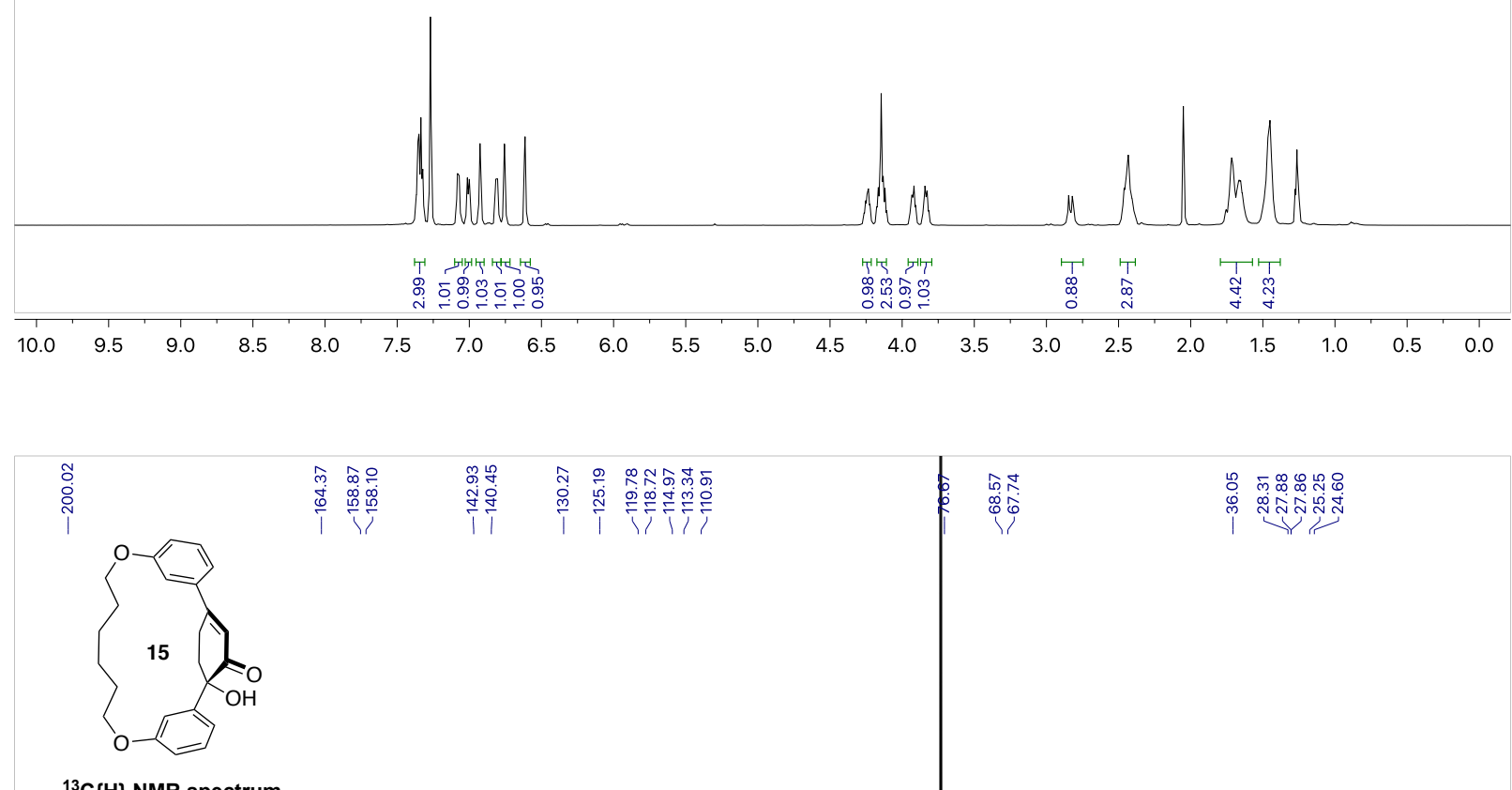

${ }^{13} \mathrm{C}\{\mathrm{H}\}$ NMR spectrum

(151 MHz, $\mathrm{CDCl}_{3}$ )
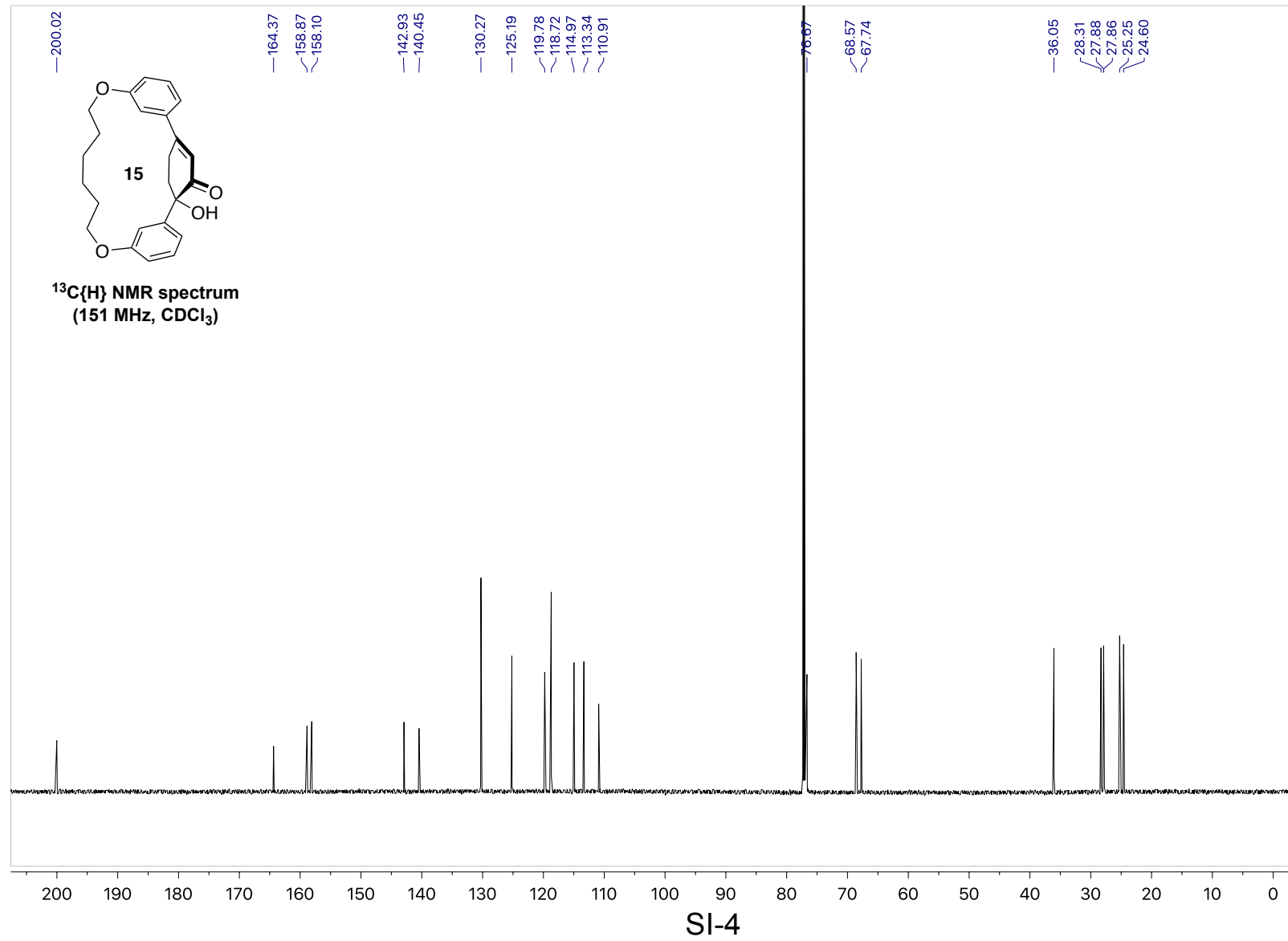

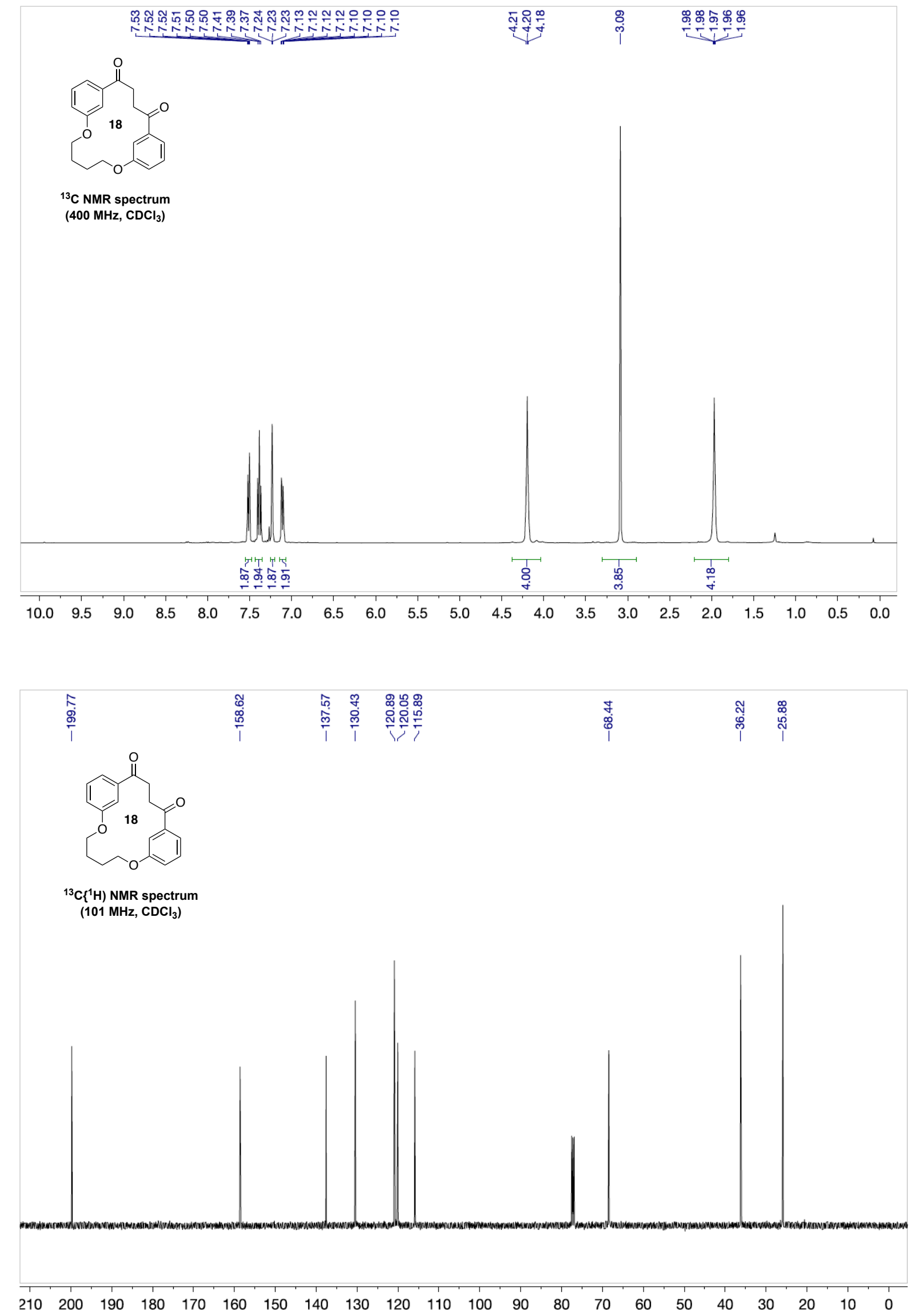

SI-5 

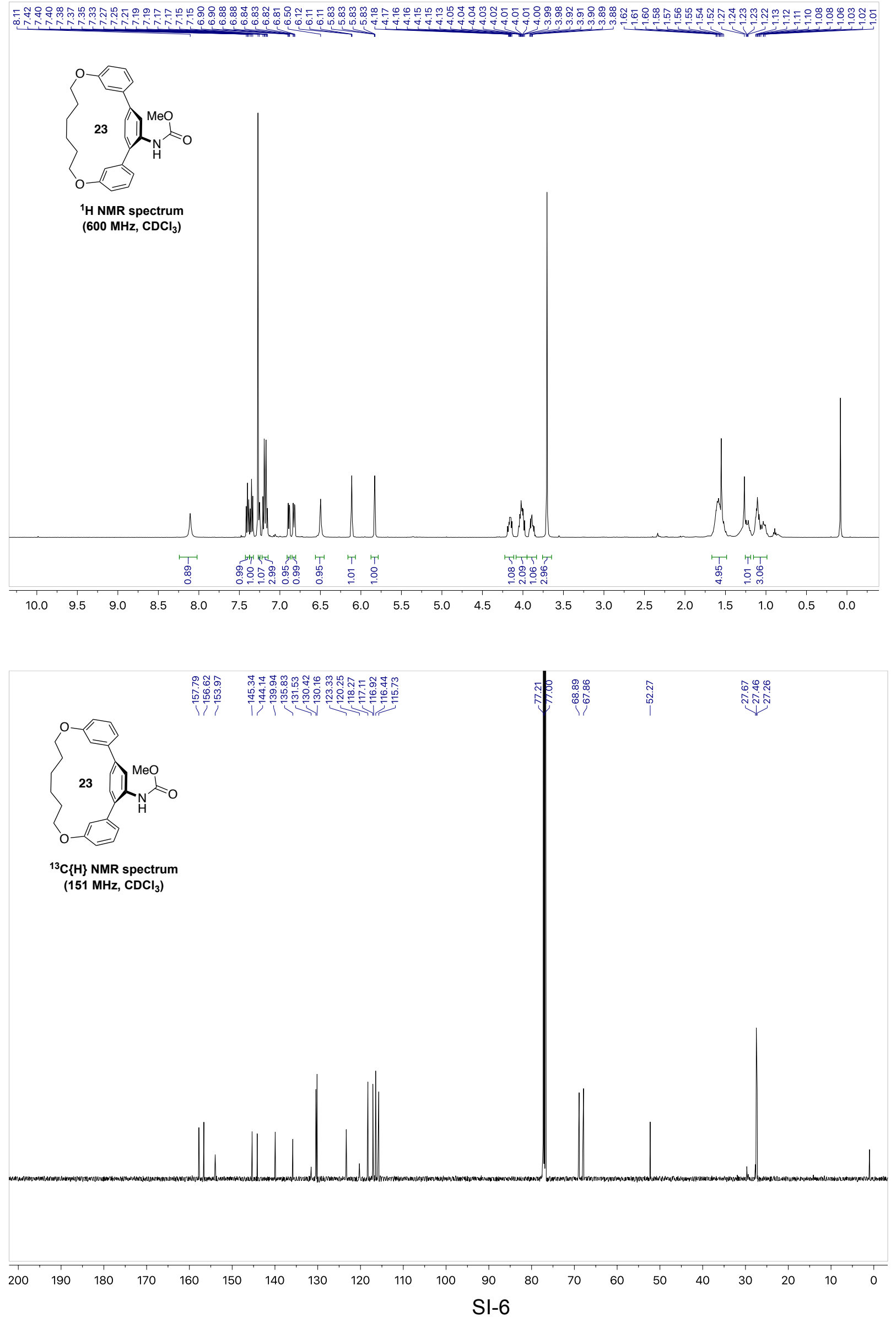

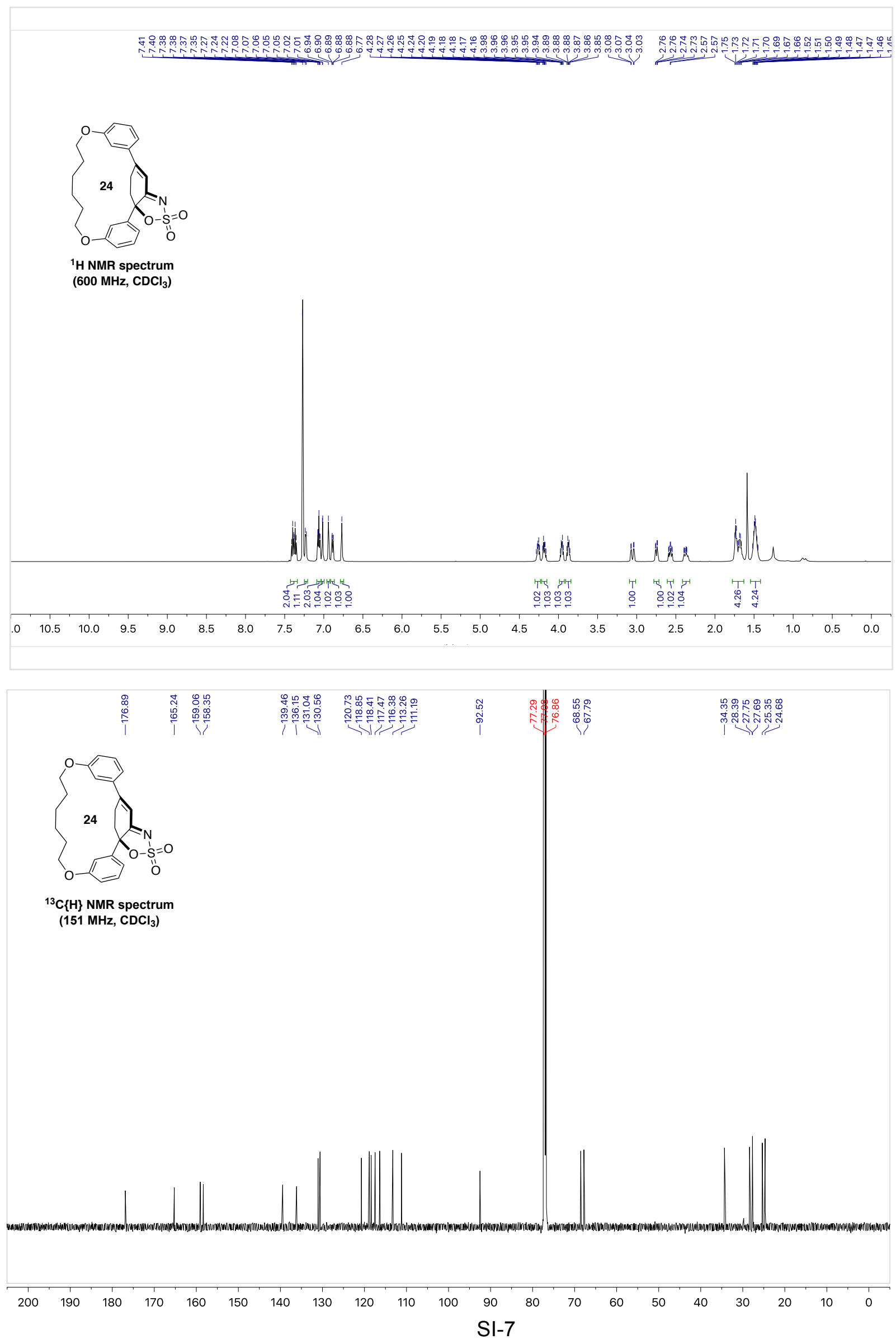

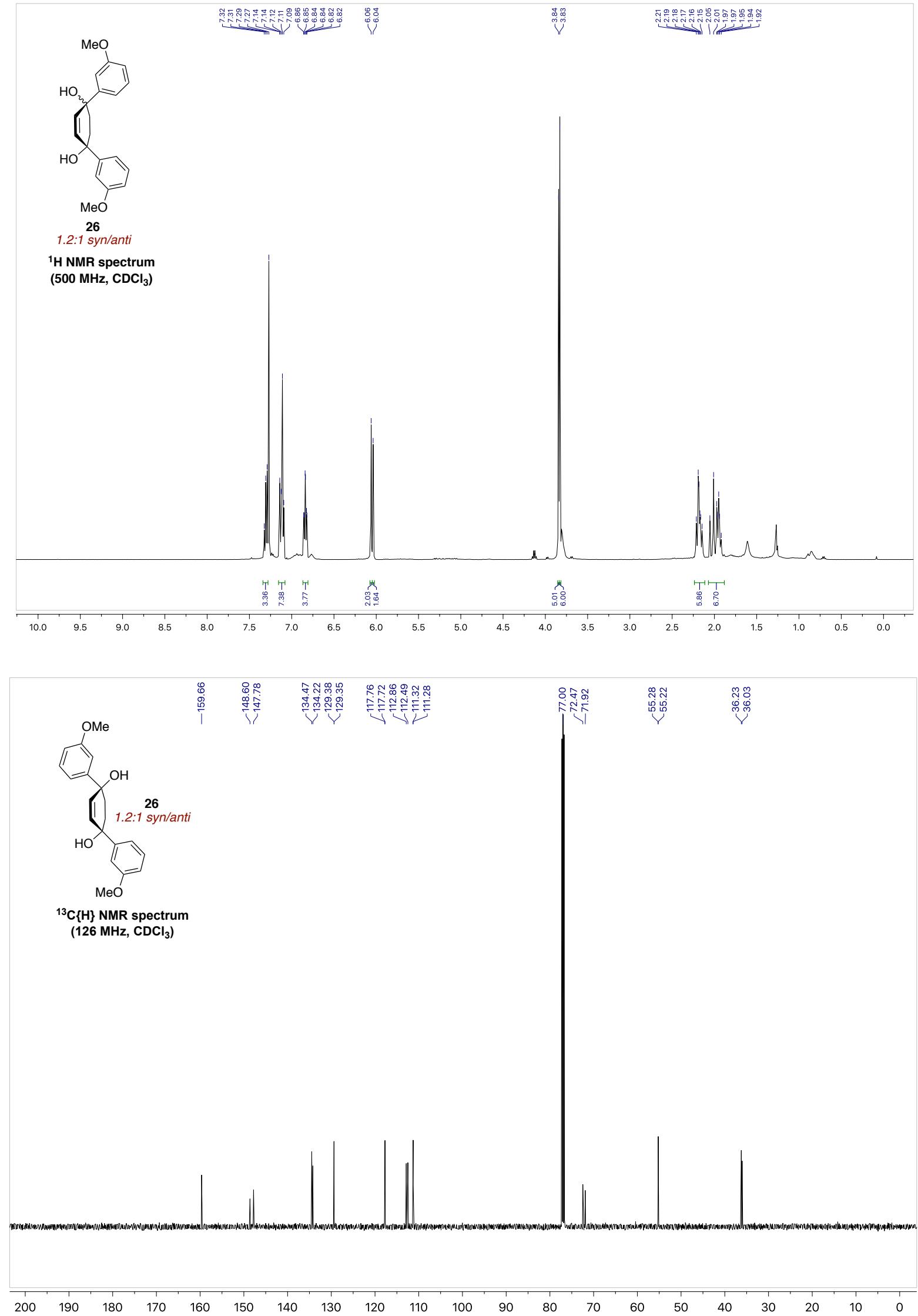

SI-8 

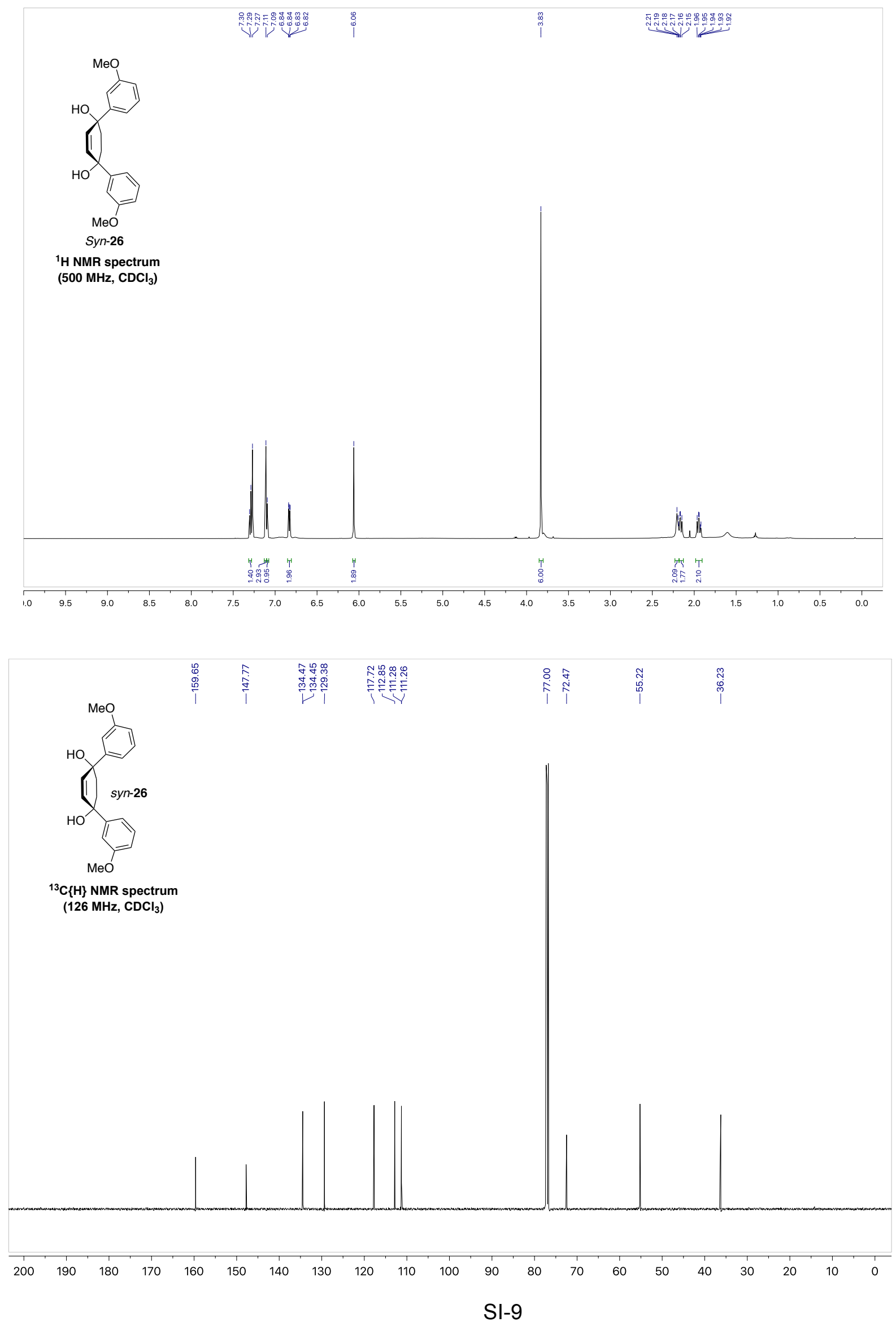

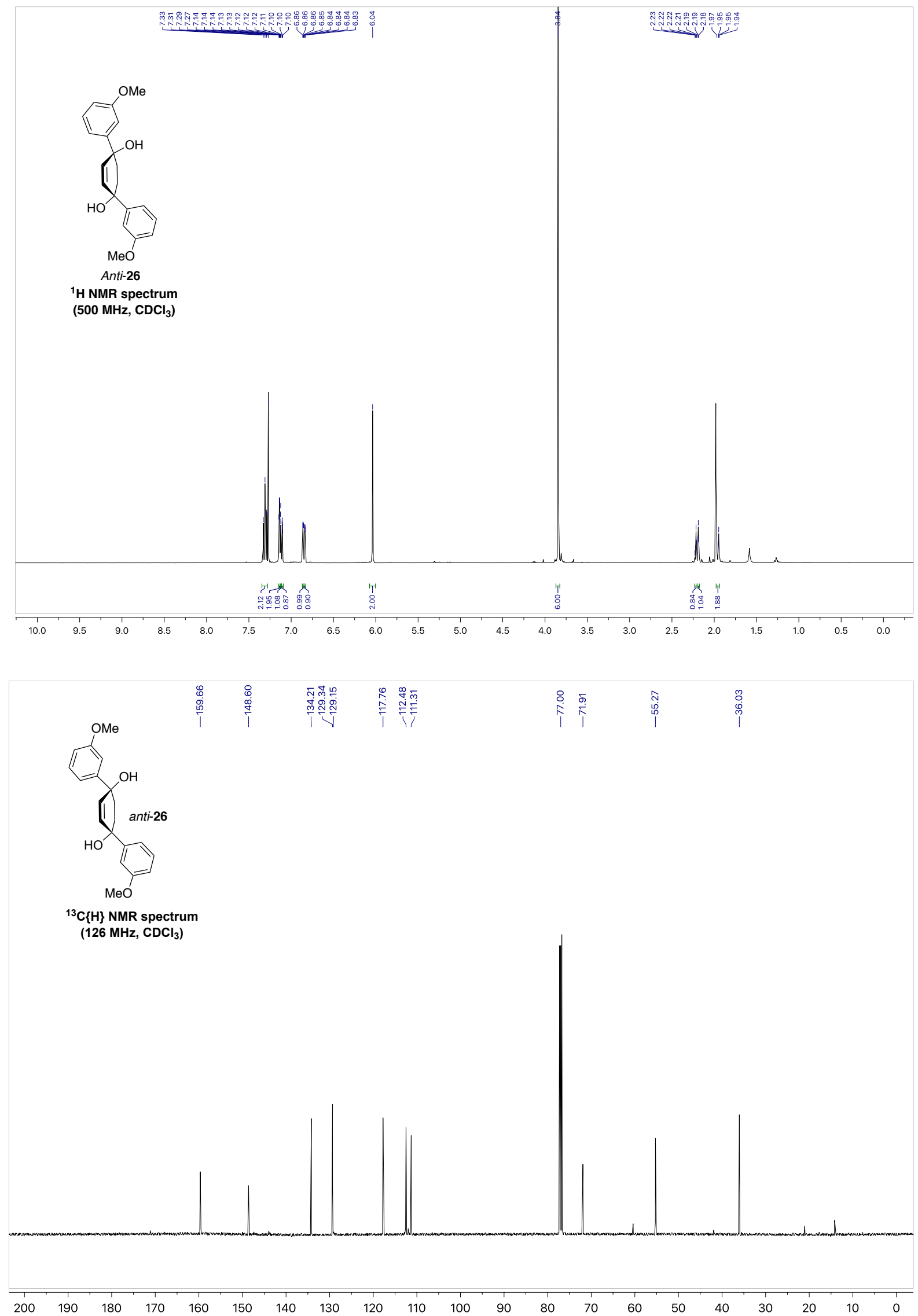

SI-10 

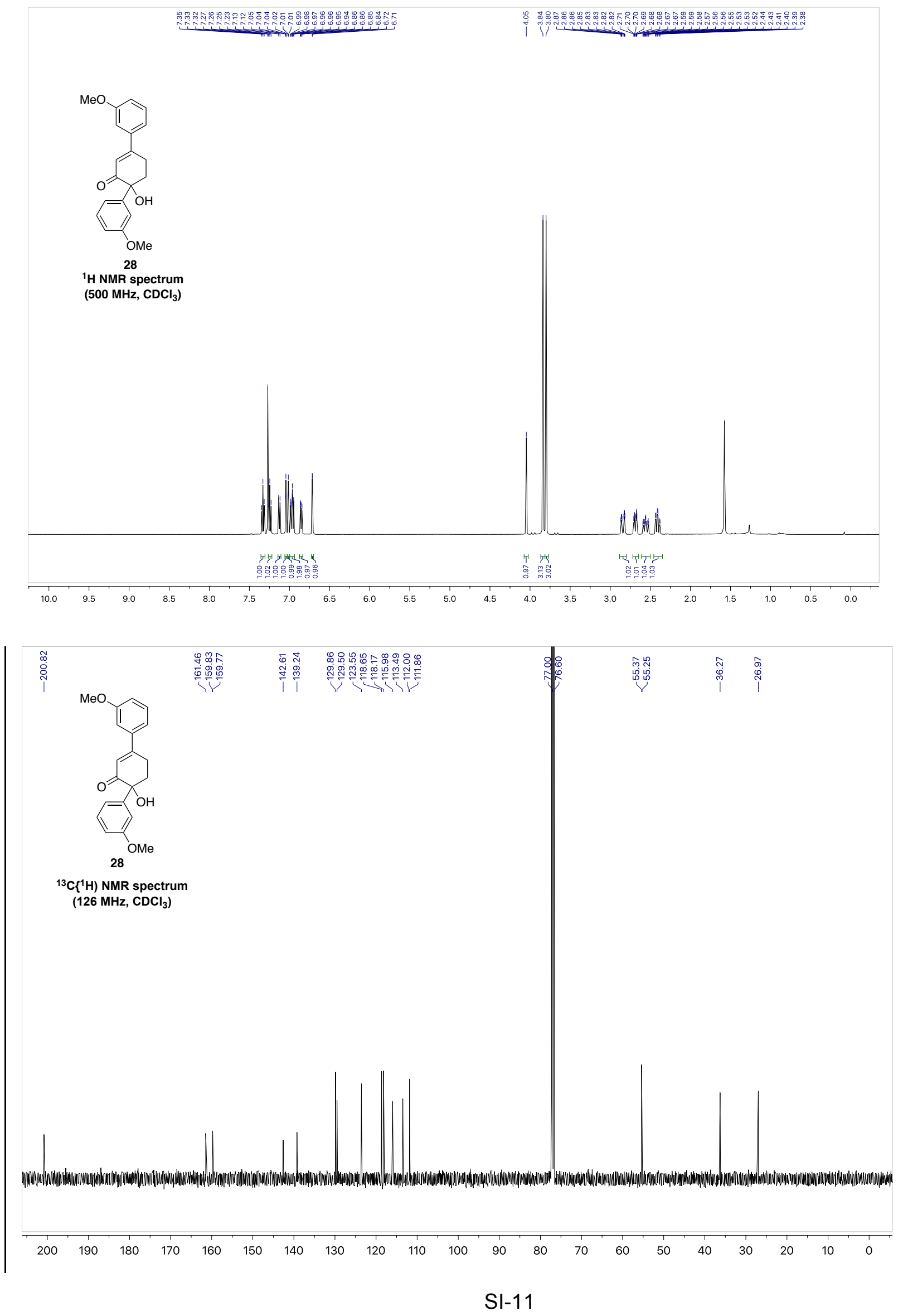

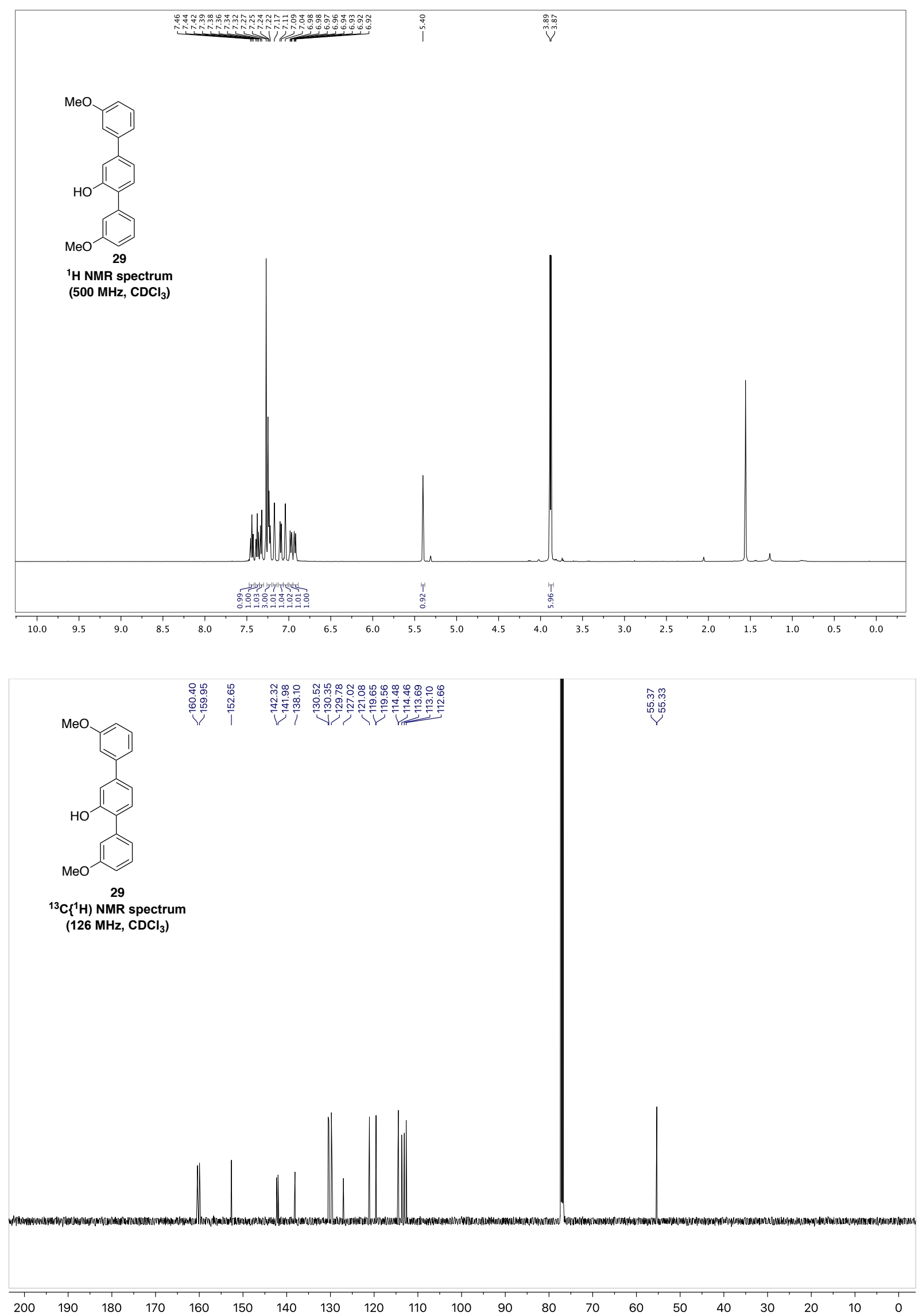

$90 \quad 80$

SI-12 

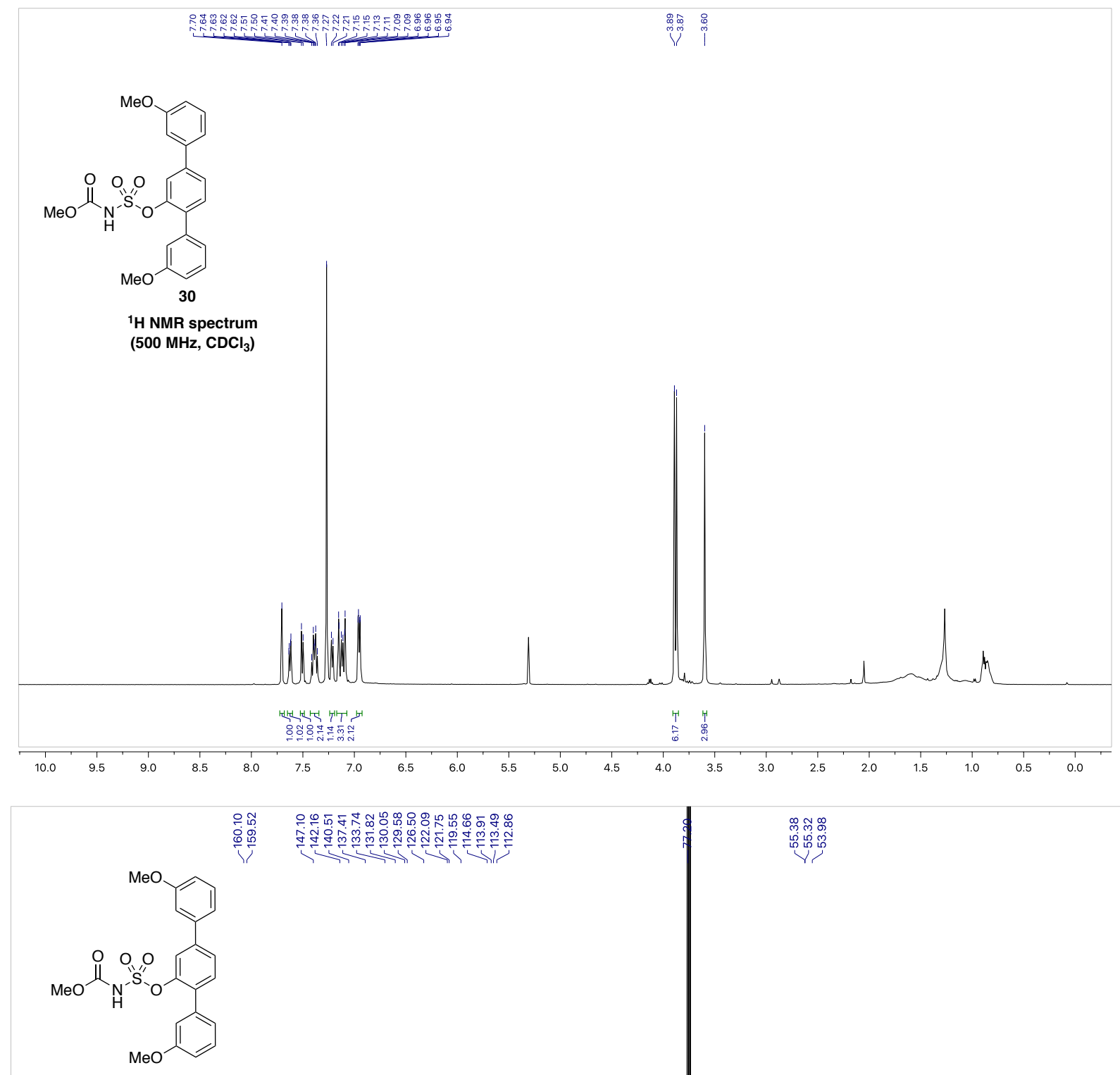

${ }^{13} \mathrm{C}\left\{{ }^{1} \mathrm{H}\right)$ NMR spectrum

(126 MHz, $\mathrm{CDCl}_{3}$ )

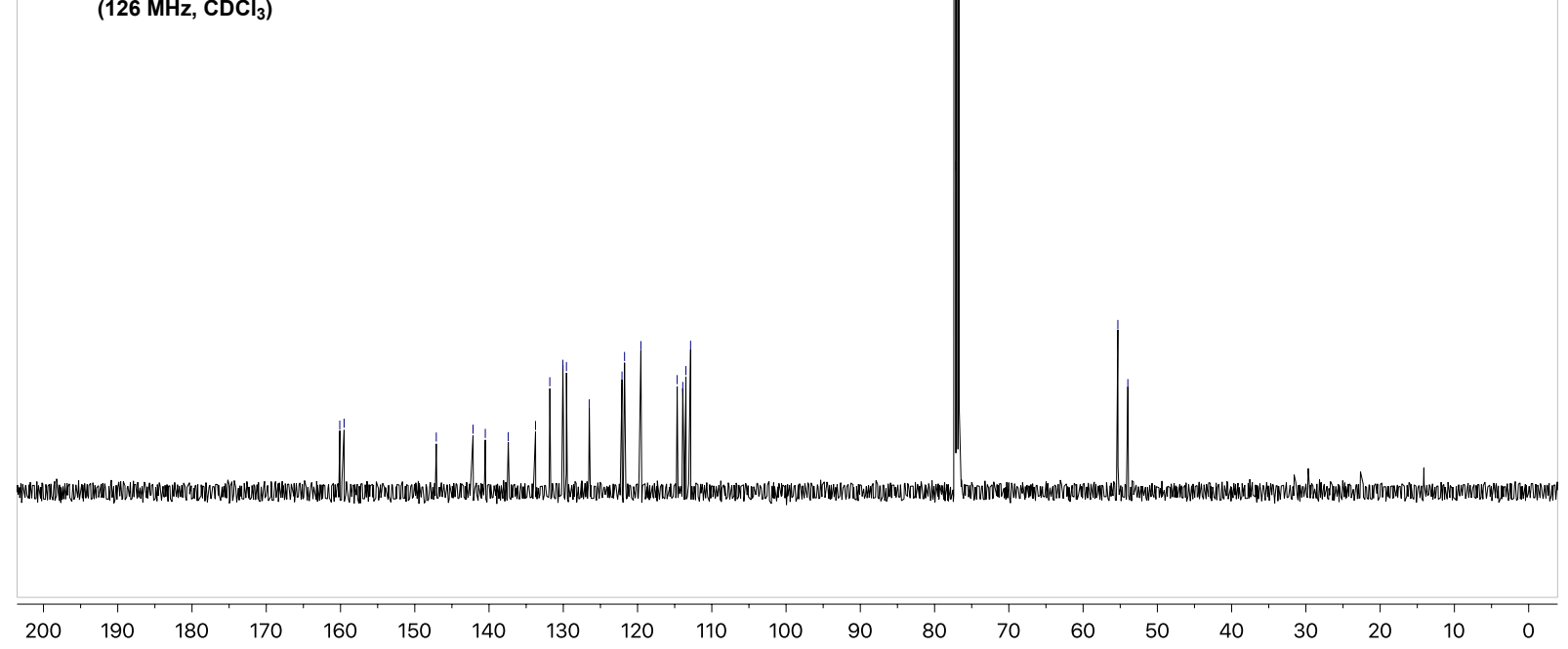

SI-13 

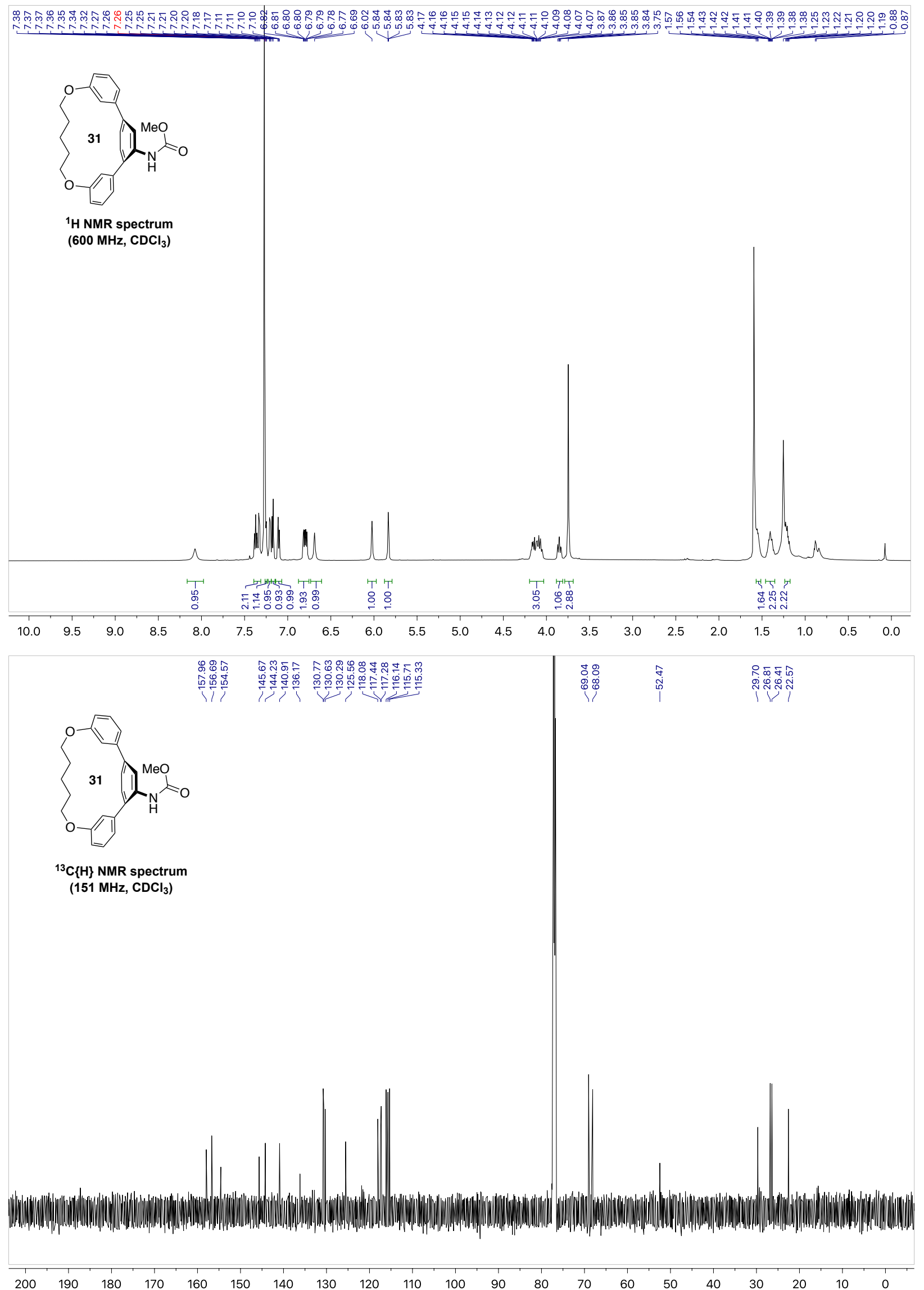

SI-14 


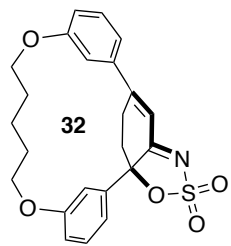

${ }^{1} \mathrm{H}$ NMR spectrum $\left(600 \mathrm{MHz}, \mathrm{CDCl}_{3}\right.$ )
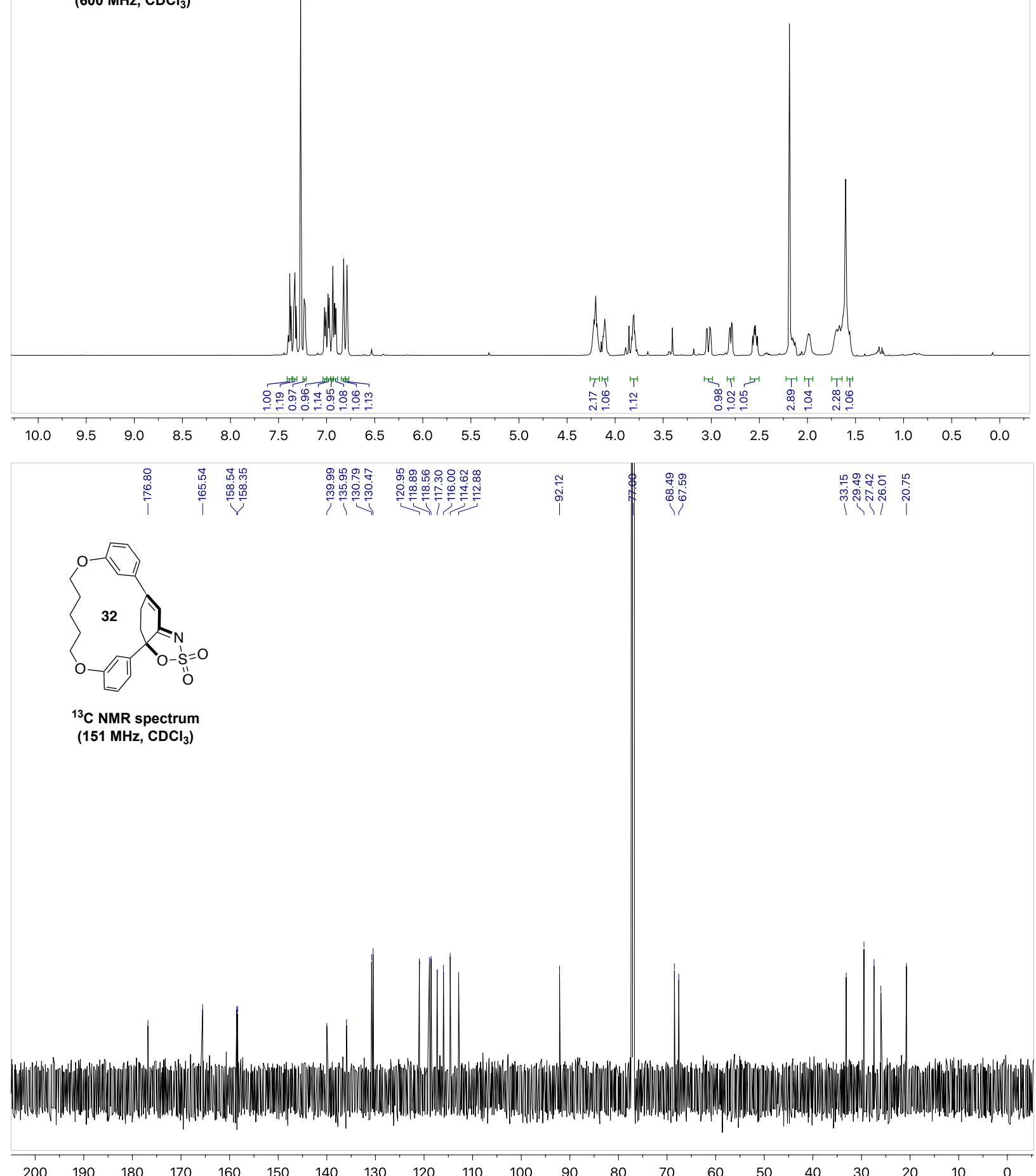


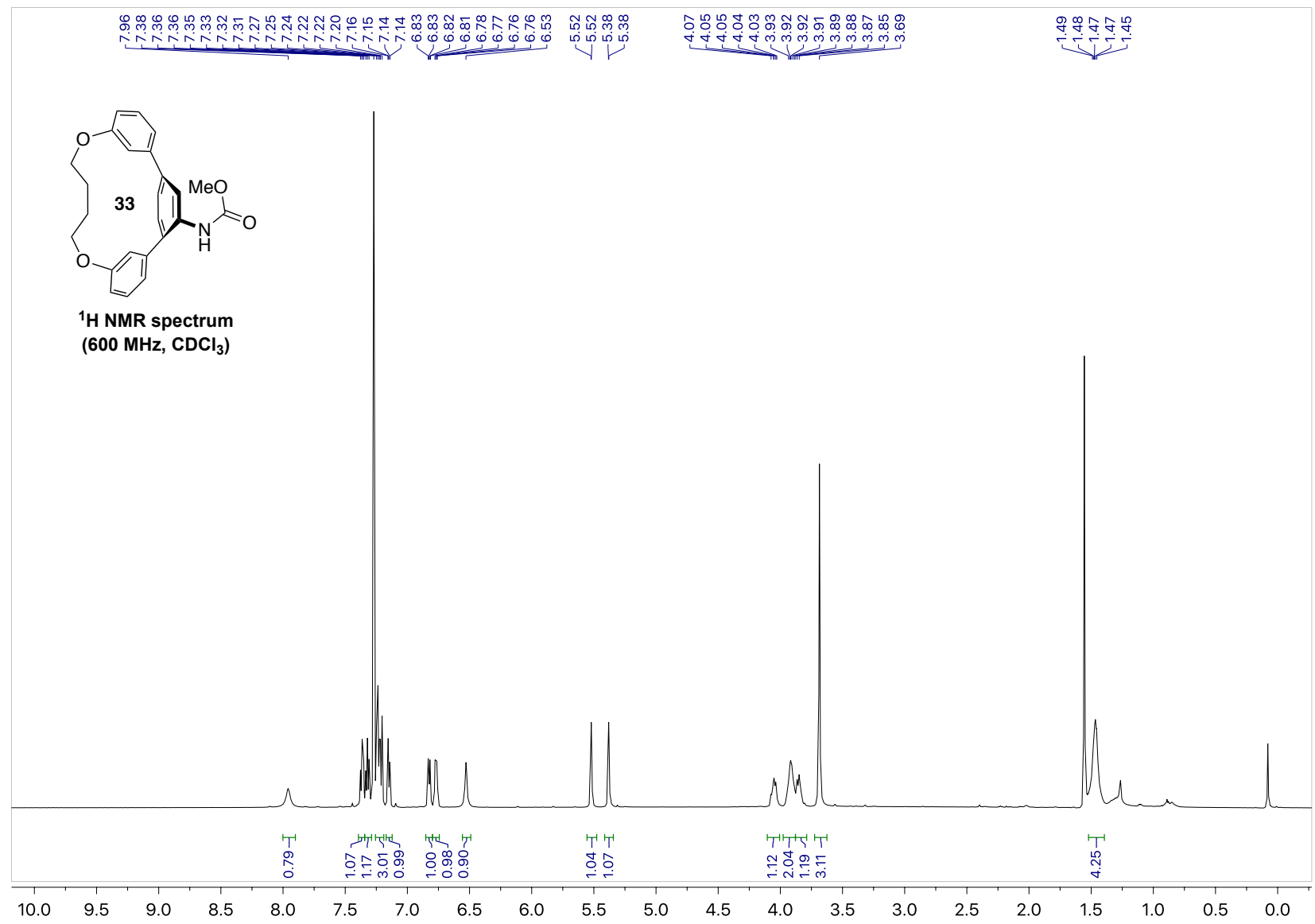

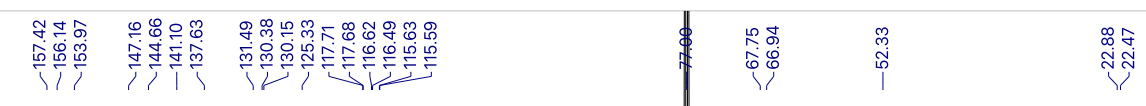

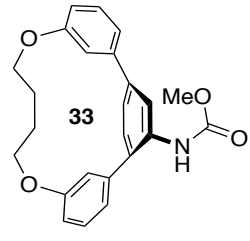

${ }^{13} \mathrm{C}$ NMR spectrum $\left(151 \mathrm{MHz} \mathrm{CDCl}_{3}\right.$ )

$\begin{array}{llllllllll}190 & 180 & 170 & 160 & 150 & 140 & 130 & 120 & 110 & 100 \\ & & & & & & & & & \text { Sl- } 16\end{array}$ 

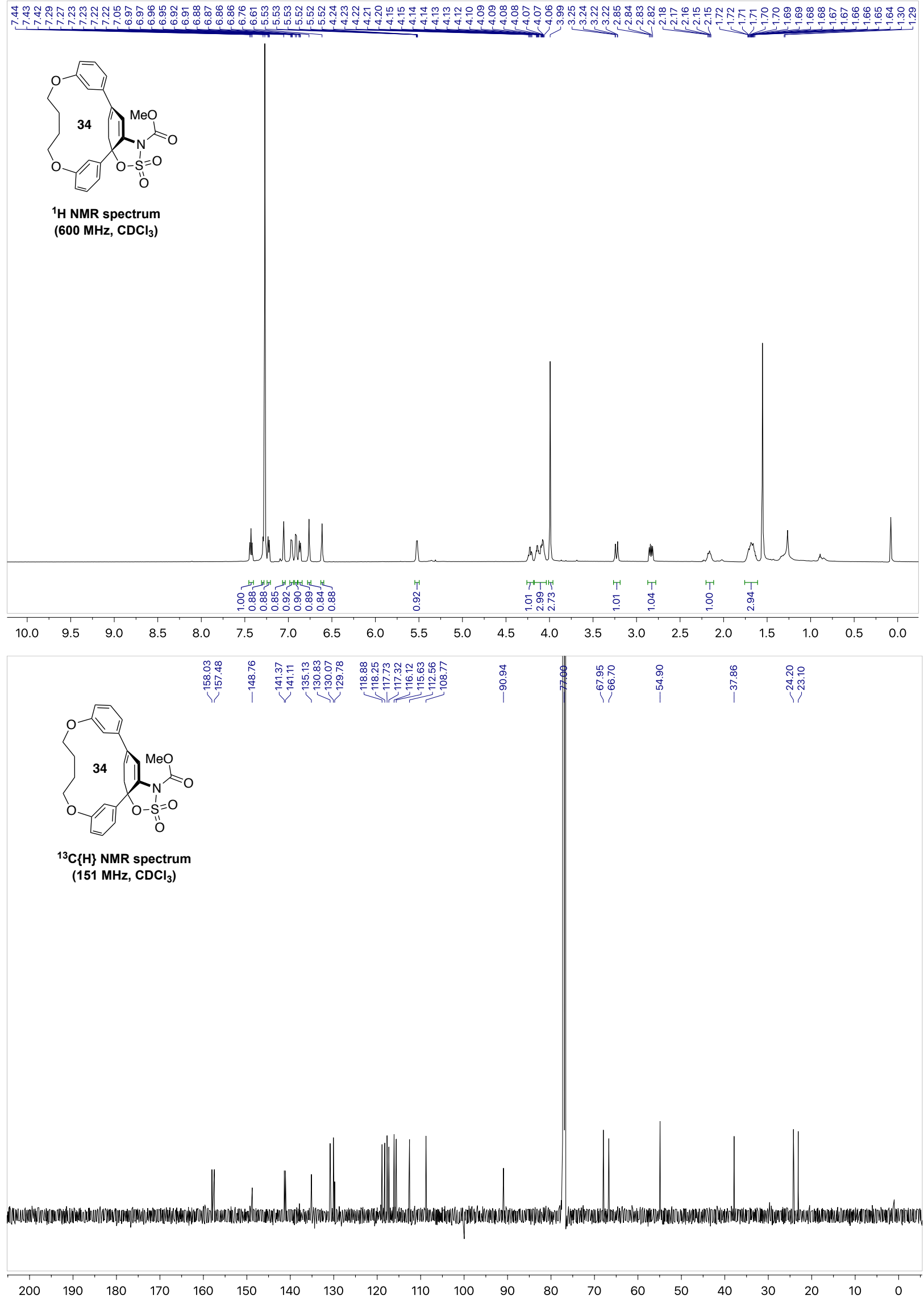


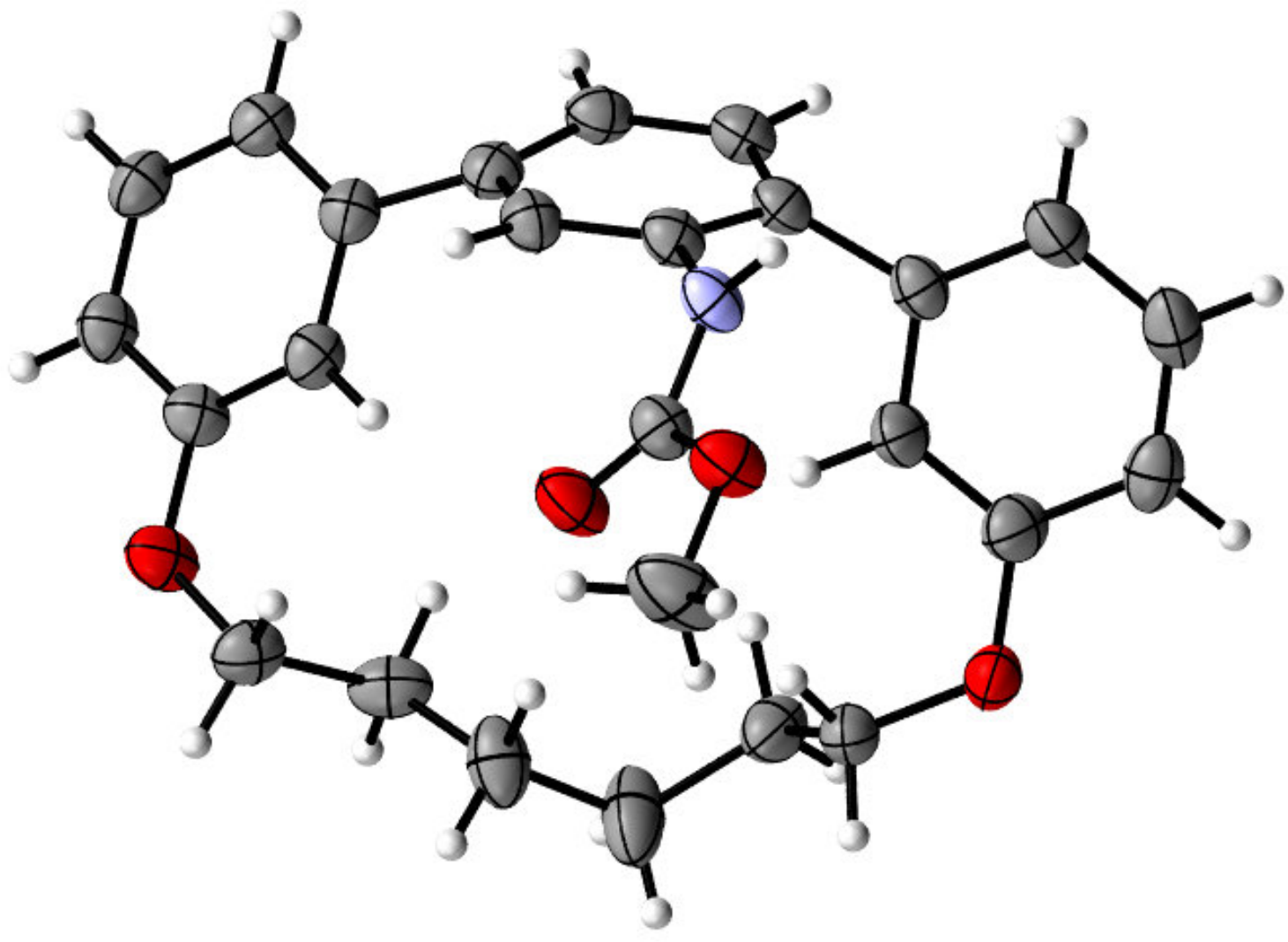

Figure SI-1: Thermal ellipsoid representation of 23. Ellipsoids are displayed at $50 \%$ probability level.

Table SI-2: Crystal data and structure refinement for (snjp72) compound 23.

Identification code
Chemical formula
Formula weight
Temperature
Wavelength
Crystal size
Crystal habit
Crystal system
Space group
Unit cell dimensions

Volume

Z

Density (calculated) Absorption coefficient Diffractometer

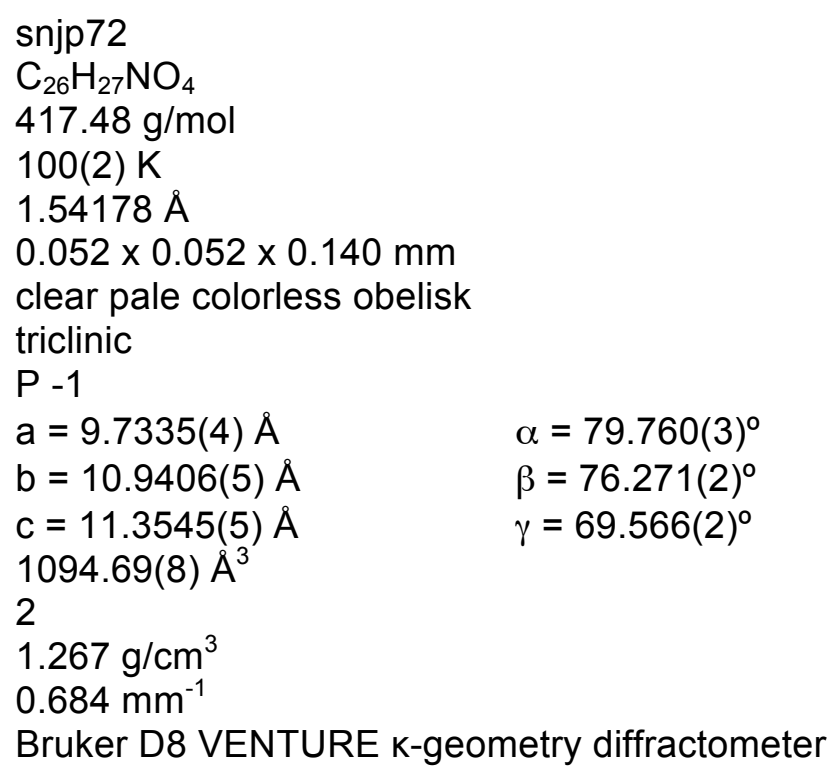




\section{Radiation source}

Theta range for data collection Index ranges

Reflections collected

Independent reflections

Coverage of independent reflections

Absorption correction

Max. and min. transmission

Structure solution technique

Structure solution program

Refinement method

Refinement program

Function minimized

Data / restraints / parameters

Goodness-of-fit on F2

$\Delta / \sigma_{\max }$

Final $R$ indices

Weighing scheme

Largest diff. peak and hole

R.M.S. deviation from mean
Incoatec I $\mu$ S DIAMOND microfocus sealed tube (Cu Ka, $\lambda=1.54184 \AA$ )

5.43 to $79.71^{\circ}$

$-10<=\mathrm{h}<=8,-26<=\mathrm{k}<=27,-15<=\mathrm{l}<=15$

47853

$4443[\mathrm{R}$ (int) $=0.0443]$

$94.50 \%$

Multi-Scan

0.6320 and 0.4560

direct methods

XT, VERSION 2014/5

Full-matrix least-squares on $\mathrm{F}^{2}$

SHELXL-2018/3 (Sheldrick, 2018)

$\Sigma \mathrm{w}\left(\mathrm{F}_{\mathrm{o}}^{2}-\mathrm{F}_{\mathrm{c}}{ }^{2}\right)^{2}$

$4443 / 0 / 280$

1.042

0.002

4400 data; $I>2 \sigma(I) \quad R 1=0.0365, w R 2=0.0969$

all data

$R 1=0.0367, w R 2=0.0971$

$w=1 /\left[\sigma^{2}\left(F_{o}{ }^{2}\right)+(0.0505 P)^{2}+1.0525 P\right]$

where $\mathrm{P}=\left(\mathrm{F}_{\mathrm{o}}{ }^{2}+2 \mathrm{~F}_{\mathrm{c}}{ }^{2}\right) / 3$

0.337 and $-0.474 \mathrm{e}^{-3}$

$0.047 \mathrm{e}^{-3}$ 


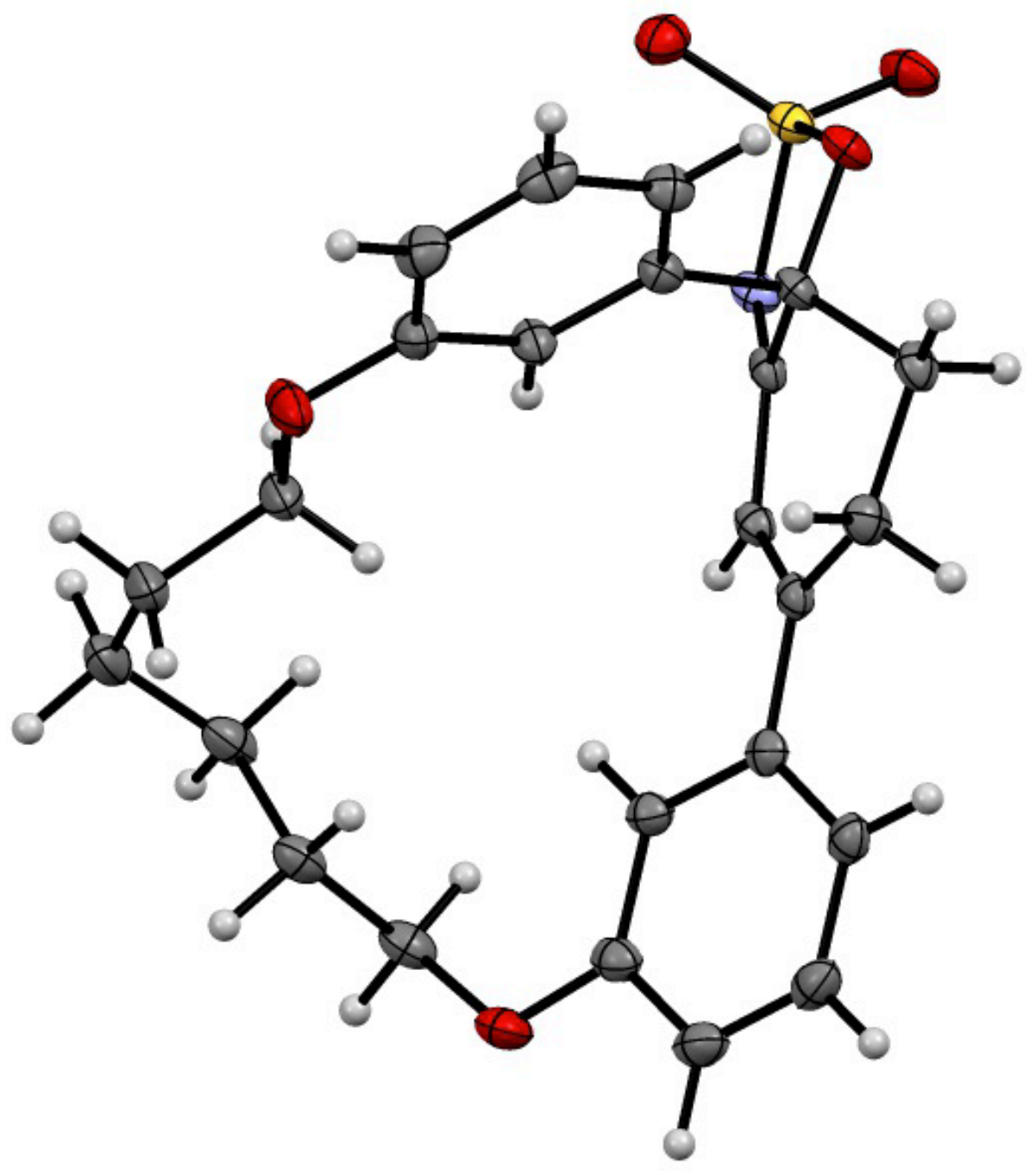

Figure SI-2: Thermal ellipsoid representation of 24. Ellipsoids are displayed at $50 \%$ probability level.

Table SI-3: Crystal data and structure refinement for (snj_167) compound 24.

Identification code
Chemical formula
Formula weight
Temperature
Wavelength
Crystal size
Crystal habit
Crystal system
Space group
Unit cell dimensions

Volume

Z

Density (calculated) snj_167

$\mathrm{C}_{25} \mathrm{H}_{25} \mathrm{NO}_{4} \mathrm{~S}$

$435.54 \mathrm{~g} / \mathrm{mol}$

$120(2) \mathrm{K}$

$1.54184 \AA$

$0.307 \times 0.377 \times 0.568 \mathrm{~mm}$

clear colorless rectangle

monoclinic

$\mathrm{P} 2(1) / \mathrm{c}$

$\mathrm{a}=8.2149(4) \AA$

$\alpha=90^{\circ}$

$b=21.7244(10) \AA$

$c=12.1689(17) \AA$

$2151.80(17) \AA^{3}$

$\beta=97.7635(13)^{\circ}$

$\gamma=90^{\circ}$
4

$1.357 \mathrm{~g} / \mathrm{cm}^{3}$

SI-20 
Absorption coefficient

Diffractometer

Radiation source

Theta range for data collection

Index ranges

Reflections collected

Independent reflections

Coverage of independent reflections

Absorption correction

Max. and min. transmission

Structure solution technique

Structure solution program

Refinement method

Refinement program

Function minimized

Data / restraints / parameters

Goodness-of-fit on F2

$\Delta / \sigma_{\max }$

Final $\mathbf{R}$ indices

Weighing scheme

Largest diff. peak and hole

R.M.S. deviation from mean
$1.643 \mathrm{~mm}^{-1}$

Bruker D8 VENTURE k-geometry diffractometer Incoatec I $\mu$ S DIAMOND microfocus sealed tube (Cu Ka, $\lambda=1.54184 \AA$ )

5.43 to $79.71^{\circ}$

$-10<=\mathrm{h}<=8,-26<=\mathrm{k}<=27,-15<=\mathrm{l}<=15$

47853

$4443[\mathrm{R}$ (int) $=0.0443]$

$94.5 \%$

Multi-Scan

0.6320 and 0.4560

direct methods

XT, VERSION 2014/5

Full-matrix least-squares on $\mathrm{F}^{2}$

SHELXL-2018/3 (Sheldrick, 2018)

$\Sigma w\left(F_{o}^{2}-F_{c}^{2}\right)^{2}$

$4443 / 0 / 280$

1.042

0.002

4400 data; $\mid>2 \sigma(I) \quad R 1=0.0365, w R 2=0.0969$

all data

$\mathrm{R} 1=0.0367, \mathrm{wR} 2=0.0971$

$w=1 /\left[\sigma^{2}\left(F_{o}^{2}\right)+(0.0505 P)^{2}+1.0525 P\right]$

where $\mathrm{P}=\left(\mathrm{F}_{\mathrm{o}}{ }^{2}+2 \mathrm{~F}_{\mathrm{c}}{ }^{2}\right) / 3$

0.337 and $-0.474 \mathrm{eA}^{-3}$

$0.047 \mathrm{e}^{-3}$ 